\title{
Screening Study on High Power IGBT
}

\author{
M. Karama ${ }^{1 \mathrm{a}}$, F. Rabier ${ }^{1}$ \\ ${ }^{1}$ Université de Toulouse, INPT, ENIT, LGP, 47 avenue Azereix, BP1629, Tarbes, France
}

Received 10 December 2009, Accepted 15 February 2010

\begin{abstract}
This paper presents the modelling of some high power IGBT (Insulated Gate Bipolar Transistor) performances. These IGBT are essential components of the power converter in railway applications. Modelling methodology used in this study is design of experiments (DOE). The number of test in this kind of investigation is related with the number of factors. It is important before modelling to measure the effect of factors and interactions to suppress no significant factors and consequently, reduce the size of the DOE. In this paper we identify the significant elements among four factors related to converter design $\left(\mathrm{L}_{\mathrm{com}}, \mathrm{L}_{\mathrm{ge}}\right.$ ) and driver (ton, $\mathrm{R}_{\mathrm{goff}}$ ). Screening study on this factors show that only $\mathrm{L}_{\text {com }}$, $\mathrm{R}_{\mathrm{goff}}$ and to determine overvoltage and only $\mathrm{R}_{\mathrm{goff}}$ and $\mathrm{t}_{\mathrm{on}}$ determine commutation speed. Significant interactions are also identified. Lots of articles discuss about high power IGBT. This one gets onto IGBT behaviour with an experimental way.
\end{abstract}

Keywords:

\section{Introduction}

Railway applications are very developed nowadays and major part of them used electrical energy. In a train, electrical power is forwarded to traction motors by the power supply. This device is composed by three main organs which are the transformer, the redresser and the power converter.

This paper deals with power converter reliability and more precisely with the main part of this product, the IGBT (Insulated Gate Bipolar Transistor). The objective of this study is to modelling dynamic performances occurring during turn off. The work describes here is screening part it means identification of the influent factors and interactions on the observed performances, over voltage and commutation speed. This study permits to determine an additive model. This model is validated for discrete values -1 and 1 for each factor. Influent factors are identifying by a high coefficient in this model, statistical analysis like ANOVA and graphical analysis.

IGBT technology appeared at the beginning of the 80 's. It is an externally controlled switch, which has the benefits of both MOSFET and Bipolar technologies, i. e., fast, easy controllable and low power losses during on-state. Usually, several IGBTs are packaged together with diodes connected in parallel with the purpose of obtaining a current bidirectional switch (power modules). In

\footnotetext{
${ }^{\text {a }}$ Corresponding author: moussa.karama@enit.fr
}

this way, power modules can support the high current ratings required in high power applications. For instance, these modules are employed in traction application in power converters, where they transform single-phased continuous signal in a three-phased alternative signal to supply traction motors.

Multichip modules for high-power IGBT devices are complex multilayered structures consisting of different materials, which have to provide a good mechanical stability, good electrical insulation properties, and good thermal conduction capabilities [1].

The IGBT modules consist on an aluminium base plate on which is mounted copper bonded ceramic substrate. On this copper bonded substrate, the silicon IGBT and diode chips are mounted. Aluminium wires (wire bonding) are soldered by ultrasonic system on the chip pads. Figure 1 illustrates all the described parts of an IGBT module. Table 1 summarises the main materials employed for their manufacturing.

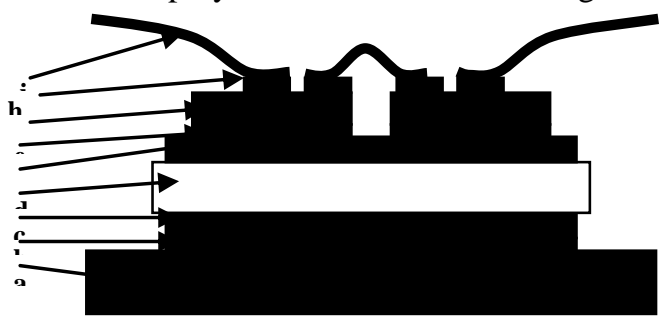

Fig. 1. IGBT module structure 
Table 1: Materials used in IGBT module structure

\begin{tabular}{|c|c|c|c|c|}
\hline & Layer & Material & $\begin{array}{c}\text { Thickness } \\
(\mu \mathrm{m})\end{array}$ & $\begin{array}{c}\mathrm{CTE} \\
\left(\mathrm{ppm} /{ }^{\circ} \mathrm{c}\right)\end{array}$ \\
\hline $\mathrm{i}$ & Wire bond & $\mathrm{Al}$ & 300 & 22 \\
\hline $\mathrm{h}$ & Chip pad & $\mathrm{Al}+\mathrm{Si}$ & few & Compliant \\
\hline $\mathrm{g}$ & Chip & $\mathrm{Si}$ & 250 & 3 \\
\hline $\mathrm{f}$ & Solder & $\begin{array}{c}\mathrm{SnPb} \text { or } \\
\mathrm{SnAg}\end{array}$ & 100 & Compliant \\
\hline $\mathrm{e}$ & \multirow{3}{*}{$\begin{array}{l}\text { Metal- } \\
\text { coated } \\
\text { substrate }\end{array}$} & $\mathrm{Cu}$ & 280 & $\begin{array}{c}\text { Not } \\
\text { Relevant }\end{array}$ \\
\hline d & & $\begin{array}{l}\mathrm{Al} 2 \mathrm{O} 3 \\
\text { or AlN }\end{array}$ & 1000 & 7 or 4 \\
\hline $\mathrm{c}$ & & $\mathrm{Cu}$ & 280 & $\begin{array}{c}\text { Not } \\
\text { Relevant }\end{array}$ \\
\hline b & Solder & $\begin{array}{c}\mathrm{SnPb} \text { or } \\
\mathrm{SnAg}\end{array}$ & 180 & Compliant \\
\hline $\mathrm{a}$ & Base plate & $\begin{array}{l}\mathrm{Cu} \text { or } \\
\mathrm{AlSiC}\end{array}$ & 4000 & 17 or 8 \\
\hline
\end{tabular}

Acceleration and deceleration cycles during a train commercial service, together with the IGBTs and diode switching, produce thermal cycling phenomena inside the module. These internal temperature variations associated to the mismatch of the thermal expansion coefficients (CTE) and the thickness differences between the layers in contact induce important shearing constrains at the layer interfaces [1]. For medium and high power component used in traction application, thermal cycling is the main failure cause [2]. The thermal cycles experienced by the components induce different phenomena which can produce at long term the component breakdown. The most common failure mechanisms are wire bonding lift off [3] and solder fatigue [4, 5]. All these thermal cycling consequences and other failure mechanisms are presented in $[1,2]$.

\section{Modelling IGBT performances}

To answer this problem, IGBT industrial experts gives importance on IGBT behaviour during turn off in particular for the overvoltage and the commutation speed.

The objective of this study is to modelling IGBT performances it means overvoltage and commutation speed during turn off. The chosen method to establish these models is design of experiments (DOE).

Design of experiments method appears in the 20 's with the work of Sir Ronald Aymler Fisher
(1890-1962). This method determines a relation between the studied response and factors which can affect this response and can be modify by the experimenter.

The purpose of design of experiment is to organise experiments intelligently in order to obtain the maximum of information using a minimum of arrays [6].

Design of experiment method is employed to answer two kinds of problems:

- Screening problems;

- Response surface method (RSM).

Screening method allows to identify statistically influent factors on the response variations among all the factors of the study. This method is applied to simplify a problem. In this case the goal is to know why there is a response variation. It is also possible to evaluate interactions effect and identify influent interactions.

All variations of a factor level induce response variation. This variation can be caused by two different sources:

- Factor effect on the response value;

- Variation of the factors associated of the experimentation considered as fixed but which can lightly vary from an experiment to another (experimental error).

In screening studies, researched model is additive:

$$
Y=C^{t e}+\sum_{i=1}^{k} W_{i}
$$

For a study without interaction evaluation.

$$
Y=C^{t e}+\sum_{i=1}^{k} W_{i}+\sum_{i=1}^{k-1} \sum_{j=i+1}^{k} C_{i j}
$$

For a study including first order interactions.

With: Y-the measured response, k-the number of factors, Wi-the effect of the $\mathrm{i}$ factor, $\mathrm{Cij}$ - the effect of the interaction between factors $i$ and $j$.

In this case, it is this kind of model we want to determine.

The number of coefficient in the model is:

$$
p=1+\sum_{i=1}^{k}\left(m_{i}-1\right)
$$

for a study without interaction evaluation;

$$
p=1+\sum_{i=1}^{k}\left(m_{i}-1\right)+\sum_{i=1}^{k-1} \sum_{j=i+1}^{k}\left(m_{i}-1\right)\left(m_{j}-1\right)
$$

for a study including first order interactions. 
with: p-the number of model's unknown, k- the number of factors, mi-the number of interactions of the i factor.

For design example of experiments for studies including only factors without interaction, we can mentioned the work of Placket and Burman [7] who propose experimental designs where the number of arrays $p$ is the multiple of 4 directly superior of the number of unknown of the model without interaction.

Among the different design of experiments allowing interactions study, Rechtschaffner designs are interesting [8]. It is saturated design of experiment it means that the number of tests is strictly equal to the number of model's unknown.

When we talk about design of experiment for screening, we cannot not mentioned G. Taguchi's work [9]. Taguchi's tables are established for defined number of factors with defined number of modalities and only some of interactions are observed.

Last evolution in design of experiments dedicate to screening studies concerns optimal design. Its methods permit to build experimental matrix "à la carte". Each factor can have it own number of modality and only the interesting interactions are include of the model. Optimal designed respects algorithmic laws and optimise algebraic criteria defined by [10].

Screening design of experiment is employed in [11]. In this paper the author reduce factor number to take in account thanks to a screening study using a Plackett-Burman regression model. With this method, he identifies in a group of 21 factors, the 10 really influent factors using 28 arrays.

This study deals also with screening method to determinate the factors which must be present in the final models. These models will be established later using RSM method.

With design of experiment following response surface method (RSM), the user tries to explain how the response evolves in the experimental area.

RSM can be applied in different cases:

- Optimization (minimization, maximization or target value) of one or several responses;

- Research of a compromise between several responses;

- Construction of the response variation in the experimental area.

In RSM study, response must be traduced in second order polynomial model:

$$
\eta=\alpha_{0}+\sum_{i=1}^{k} \alpha_{i} x_{i}+\sum_{i=1}^{k} \alpha_{i i} x_{i}{ }^{2}+\sum_{i=1}^{k-1} \sum_{j=i+1}^{k} \alpha_{i j} x_{i} x_{j}
$$

with: $\alpha_{0}$-the constant of the model, $\alpha_{\mathrm{i}}$-the coefficient of the factor $\mathrm{i}$ evaluated with least square method, $\mathrm{x}_{\mathrm{i}}$-the level of factor $\mathrm{i}$.

The number of unknowns in the model for a $\mathrm{k}$ factor study is:

$$
p=\frac{(k+1)(k+2)}{2}
$$

Design of experiments for response surface is younger than design of experiments for screening study. Three articles are very important in RSM history:

- Centred composite design proposed by G.E.P. Box and K.B. Wilson in 1951 [12];

- Designs presented by G.E.P. Box and D.W. Behnken in 1960 [13];

- Doehlert matrices in 1970 [14].

Optimal design can also be applied to RSM problems.

Design for RSM needs lot of test for a large number of factors so reduction of factor number with preliminary study is very useful.

For an application of response surface method, we can refer to [15]. In this paper, the author applies a L9 design of experiment to optimize the performance of his system.

\section{Screening study}

Result analysis begins with the calculation of the model's coefficients. For this step, design of experiment is translated in the following form:

$$
(Y)=(X)(\text { Coefficien ts })+(E)
$$

With: (Y)-the response matrix, (X)-the encoded experimental matrix, (Coefficients)-the coefficients matrix, (E)-the error matrix.

Except for saturated designs of experiments, $(\mathrm{X})$ is not a square matrix. Model's coefficients calculation has recourse to the matrix expression of the least square method given by Dodge in [16]:

$$
(\text { Coefficien ts })=\left(X^{+}\right)(Y)
$$

Where $(\mathrm{X}+)$ is the pseudo inverse of the $(\mathrm{X})$ matrix define by Ben-Israel and Greville in [17] as:

$$
\left(X^{+}\right)=\left({ }^{t} X X\right)^{-1}\left({ }^{t} X\right)
$$

In a screening study, analysis of the model is very important in order to determine if each element is significant or not. Different techniques are available to answer this question. The most 
common is ANOVA but we will see that other graphical methods are also competitive.

Analyse of variance allows to reject or not the HO hypothesis according to estimated that factor variation doesn't induce response variation significantly more important than response variation caused by experimental error. The test applied in this method is Fisher-Snedecor test. The fundamental technique is a partitioning of the total sum of squares into components related to the effects in the model used.

Daniel's method [18] is another statistical method able to qualify a factor or an interaction as influent or not. This method consists in a graphic comparing the absolute value of the effect and semi-normal theoretical fractile (or quantile) obtained with the inverse of the repartition function of the reduced centered normal law named $F^{-1}\left(\frac{P+1}{2}\right)$ where $\mathrm{P}$ is define by the following relation :

$$
P=\frac{i-0,5}{k}
$$

with $\mathrm{i}$, the rank of the factor when the absolute values of the median effects are classed in increasing order and $\mathrm{k}$ the total number of model's coefficients.

Lenth's method [19] is another analysis method admits to determine if a factor or an interaction is really influent on a response. This method consists in the estimation of a pseudo typical-error, in order to realize a statistical test. The result of this test is graphically represented with a histogram where each column stands for the coefficient associated to a factor or an interaction. This histogram is completed by a limit of signification of the model elements.

\section{Experimental Simulation}

This study use double pulse commutation tests and the responses are observed during the second turn off. Each pulse corresponds to a passing phase of the IGBT module. The first pulse permits to load the current in an inductance so it length depend of the value of current we need on the second commutation.

For these tests, two IGBT modules are use, in one of them, IGBT chip are employed and in the other, diode chip are employed. The device represent one third of the power converter mounted on a train's power supply.
Screening study using four factors with two levels has been realized on IGBT modules. The observed responses were overvoltage and commutation speed $\mathrm{dV} / \mathrm{dt}$. The four factors of this study are resumed in table II.

Table 2 : Factors definition

\begin{tabular}{|c|l|l|}
\hline Factor & \multicolumn{1}{|c|}{ Description } & Limits \\
\hline A: $\mathrm{R}_{\mathrm{goff}}$ & $\begin{array}{l}\text { Gate resistance emplaced on } \\
\text { the driver. }\end{array}$ & [A1; A2] \\
\hline B: $\mathrm{L}_{\mathrm{com}}$ & $\begin{array}{l}\text { Inductance induced by the } \\
\text { converter connection which is } \\
\text { named bus-bar. }\end{array}$ & {$[\mathrm{B} 1 ; \mathrm{B} 2]$} \\
\hline $\mathrm{C}: \mathrm{L}_{\mathrm{ge}}$ & $\begin{array}{l}\text { Inductance induced by the } \\
\text { connection between driver and } \\
\text { IGBT gate. }\end{array}$ & {$[\mathrm{C} 1 ; \mathrm{C} 2]$} \\
\hline $\mathrm{D}: \mathrm{t}_{\mathrm{on}}$ & $\begin{array}{l}\text { Passing period of the second } \\
\text { pulse. }\end{array}$ & {$[\mathrm{D} 1 ; \mathrm{D} 2]$} \\
\hline
\end{tabular}

The low number of factors in this study allows us to use a full factorial design. So the design of experiment is composed by 16 tests as we can see in the following table III. With this design of experiment it's possible to obtain an additive model with first order interaction.

Table 3: Full factorial design for 4 factors with 2 levels

\begin{tabular}{|c|c|c|c|c|}
\hline Test & $\mathrm{L}_{\text {com }}$ & $\mathrm{R}_{\text {goff }}$ & $\mathrm{L}_{\text {ge }}$ & $\mathrm{t}_{\text {on }}$ \\
\hline 1 & $\mathrm{~A} 1$ & $\mathrm{~B} 1$ & $\mathrm{C} 1$ & $\mathrm{D} 1$ \\
\hline 2 & $\mathrm{~A} 1$ & $\mathrm{~B} 1$ & $\mathrm{C} 1$ & $\mathrm{D} 2$ \\
\hline 3 & $\mathrm{~A} 1$ & $\mathrm{~B} 1$ & $\mathrm{C} 2$ & $\mathrm{D} 1$ \\
\hline 4 & $\mathrm{~A} 1$ & $\mathrm{~B} 1$ & $\mathrm{C} 2$ & $\mathrm{D} 2$ \\
\hline 5 & $\mathrm{~A} 1$ & $\mathrm{~B} 2$ & $\mathrm{C} 1$ & $\mathrm{D} 1$ \\
\hline 6 & $\mathrm{~A} 1$ & $\mathrm{~B} 2$ & $\mathrm{C} 1$ & $\mathrm{D} 2$ \\
\hline 7 & $\mathrm{~A} 1$ & $\mathrm{~B} 2$ & $\mathrm{C} 2$ & $\mathrm{D} 1$ \\
\hline 8 & $\mathrm{~A} 1$ & $\mathrm{~B} 2$ & $\mathrm{C} 2$ & $\mathrm{D} 2$ \\
\hline 9 & $\mathrm{~A} 2$ & $\mathrm{~B} 1$ & $\mathrm{C} 1$ & $\mathrm{D} 1$ \\
\hline 10 & $\mathrm{~A} 2$ & $\mathrm{~B} 1$ & $\mathrm{C} 1$ & $\mathrm{D} 2$ \\
\hline 11 & $\mathrm{~A} 2$ & $\mathrm{~B} 1$ & $\mathrm{C} 2$ & $\mathrm{D} 1$ \\
\hline 12 & $\mathrm{~A} 2$ & $\mathrm{~B} 1$ & $\mathrm{C} 2$ & $\mathrm{D} 2$ \\
\hline 13 & $\mathrm{~A} 2$ & $\mathrm{~B} 2$ & $\mathrm{C} 1$ & $\mathrm{D} 1$ \\
\hline 14 & $\mathrm{~A} 2$ & $\mathrm{~B} 2$ & $\mathrm{C} 1$ & $\mathrm{D} 2$ \\
\hline 15 & $\mathrm{~A} 2$ & $\mathrm{~B} 2$ & $\mathrm{C} 2$ & $\mathrm{D} 1$ \\
\hline 16 & $\mathrm{~A} 2$ & $\mathrm{~B} 2$ & $\mathrm{C} 2$ & $\mathrm{D} 2$ \\
\hline
\end{tabular}

The following analysis deals only with commutation speed results. Least square method 
gives the model's coefficients of the following table 4.

Table 4: Model's coefficients

\begin{tabular}{|c|c|}
\hline Factor & Coefficient \\
\hline Constant & 1,540 \\
\hline $\mathrm{L}_{\text {com }}$ & $-0,016$ \\
\hline $\mathrm{L}_{\mathrm{ge}}$ & 0,014 \\
\hline $\mathrm{R}_{\mathrm{goff}}$ & $-0,327$ \\
\hline $\mathrm{t}_{\mathrm{on}}$ & $-0,204$ \\
\hline $\mathrm{L}_{\mathrm{com}} / \mathrm{L}_{\mathrm{ge}}$ & $-0,001$ \\
\hline $\mathrm{L}_{\mathrm{com}} / \mathrm{R}_{\mathrm{goff}}$ & 0,008 \\
\hline $\mathrm{L}_{\mathrm{com}} / \mathrm{t}_{\mathrm{on}}$ & $-0,007$ \\
\hline $\mathrm{L}_{\mathrm{ge}} / \mathrm{R}_{\mathrm{goff}}$ & $-0,014$ \\
\hline $\mathrm{L}_{\mathrm{ge}} / \mathrm{t}_{\mathrm{on}}$ & 0,003 \\
\hline $\mathrm{R}_{\mathrm{goff}} / \mathrm{t}_{\mathrm{on}}$ & 0,079 \\
\hline
\end{tabular}

As we can see, some of the factors and interactions have very low effect on commutation speed. ANOVA, Daniel's method and Lenth method will give us information about the factor necessity in the model. ANOVA gives the following results:

Table 5: Analyse of variance realized on $\mathrm{dV} / \mathrm{dt}$

\begin{tabular}{|c|c|c|c|c|c|c|}
\hline & SCEi & ddli & Cmi & $\mathrm{Cmi} / \mathrm{CMr}=\mathrm{z}$ & $\begin{array}{l}\text { F0,975 } \\
(\mathrm{v} 1 ; \mathrm{v} 2)\end{array}$ & conclusion \\
\hline $\mathrm{L}_{\mathrm{com}}$ & 0,004 & 1 & 0,004 & 1,675 & 10 & $\begin{array}{c}\text { not } \\
\text { influence }\end{array}$ \\
\hline $\mathrm{L}_{\mathrm{ge}}$ & 0,003 & 1 & 0,003 & 1,342 & 10 & $\begin{array}{c}\text { not } \\
\text { influence }\end{array}$ \\
\hline $\mathrm{R}_{\mathrm{goff}}$ & 1,711 & 1 & 1,711 & 745,426 & 10 & influence \\
\hline$t_{\text {on }}$ & 0,667 & 1 & 0,667 & 290,470 & 10 & influence \\
\hline $\mathrm{L}_{\mathrm{com}} / \mathrm{L}_{\mathrm{ge}}$ & 0,000 & 1 & 0,000 & 0,002 & 10 & $\begin{array}{c}\text { not } \\
\text { influence }\end{array}$ \\
\hline $\mathrm{L}_{\text {com }} / \mathrm{R}_{\text {goff }}$ & 0,001 & 1 & 0,001 & 0,432 & 10 & $\begin{array}{c}\text { not } \\
\text { influence }\end{array}$ \\
\hline $\mathrm{L}_{\mathrm{com}} / \mathrm{t}_{\mathrm{on}}$ & 0,001 & 1 & 0,001 & 0,318 & 10 & $\begin{array}{c}\text { not } \\
\text { influence }\end{array}$ \\
\hline $\mathrm{L}_{\mathrm{ge}} / \mathrm{R}_{\mathrm{goff}}$ & 0,003 & 1 & 0,003 & 1,318 & 10 & $\begin{array}{c}\text { not } \\
\text { influence }\end{array}$ \\
\hline $\mathrm{L}_{\mathrm{gg}} / \mathrm{t}_{\mathrm{on}}$ & 0,000 & 1 & 0,000 & 0,048 & 10 & $\begin{array}{c}\text { not } \\
\text { influence }\end{array}$ \\
\hline $\mathrm{R}_{\mathrm{goff}} / \mathrm{t}_{\mathrm{on}}$ & 0,100 & 1 & 0,100 & 43,783 & 10 & influence \\
\hline $\mathrm{SCE}_{\mathrm{i}}$ & 2,490 & 10 & & & & \\
\hline $\mathrm{SCE}_{\mathrm{t}}$ & 2,501 & 15 & & & & \\
\hline Résidu & 0,011 & 5 & 0,002 & & & \\
\hline
\end{tabular}

The analysis of variance identifies Rgoff, ton and the first order interaction Rgoff/ton as influent elements in the model.

Daniel's method gives the following results:

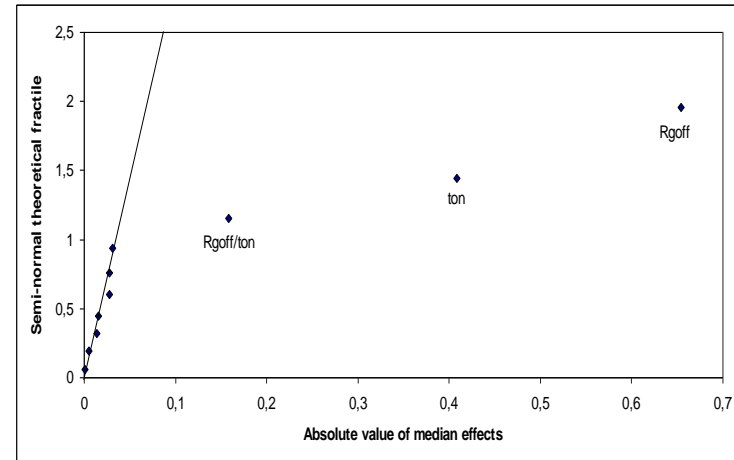

Fig. 2. Daniel's method applied on dV/dt

This method permits to identify the influent factors and first order interactions among the model's elements. In the graph, all factors which haven't influence on the response are aligned on a straight line passing by the origin of the graph.

Daniel's method identifies $\mathrm{R}_{\text {goff, }}$ ton and the first order interaction $\mathrm{R}_{\mathrm{goff}} / \mathrm{t}_{\text {on }}$ as influent elements in the model.

Lenth's method gives the following results:

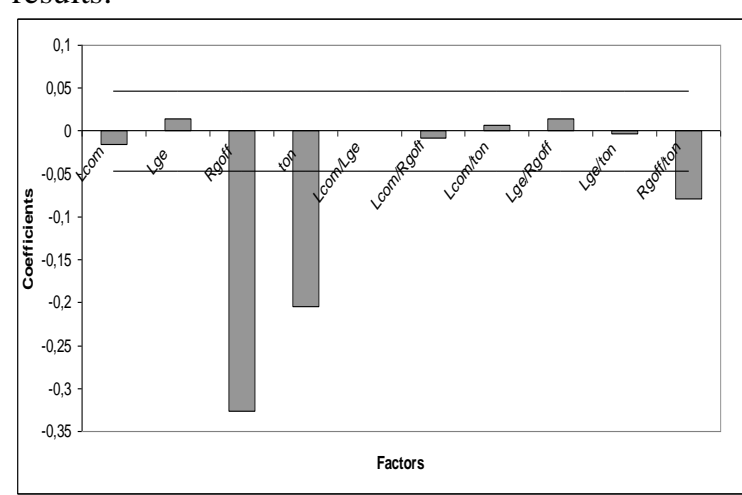

Fig. 3. Lenth's method applied on $\mathrm{dV} / \mathrm{dt}$

Straight lines are critical limits defined by Lenth in [19]. Only coefficients out of the area determined by these lines are really significant. So in this study, $\mathrm{R}_{\text {goff }}$, ton and the first order interaction $R_{\text {goff }} / t_{\text {on }}$ are significant.

All analyses gives the same results, only $R_{\text {goff }}$, ton and the first order interaction $\mathrm{R}_{\mathrm{goff}} / \mathrm{t}_{\text {on }}$ are really significant on commutation speed $\mathrm{dV} / \mathrm{dt}$.

The additive model originally from the screening study is:

$d V / d t=1,539-0,327 R_{\text {goff }}-0,204 t_{\text {on }}+0,079 R_{\text {goff }} / t_{\text {on }}(11)$

This additive model is only available on points of the full factorial design. This model is right at the considered point of the experimental area but is not able to define response behaviour between 
them. Screening objective is only the identification of significant elements of the model.

The fraction of variation of the response explained by the model $\mathrm{R}^{2}$ permit to estimate the model's quality. This metric is defined as:

$$
R^{\mathbf{2}}=\frac{S S_{R E G}}{S S}
$$

with: $\mathrm{SS}_{\mathrm{REG}}=$ the sum of squares of $\mathrm{Y}$ corrected for the mean, explained by the model.

$\mathrm{SS}=$ the total sum of squares corrected for the mean.

In our model, $\mathrm{R}^{2}=99,1 \%$, so the model can be considered as good.

Concerning overvoltage, the same study gives the following model with the influent factors:

$$
\begin{aligned}
& \Delta \mathrm{V}=47,81+10,94 \times \mathrm{L}_{\text {com }}-2,81 \times \mathrm{R}_{\text {goff }}-3,85 \times \mathrm{t}_{\text {on }}- \\
& -0,94 \times \mathrm{L}_{\text {com }} \times \mathrm{R}_{\text {goff }}-1,15 \times \mathrm{L}_{\text {com }} \times \mathrm{t}_{\text {on }}+1,35 \times R_{\text {goff }} \times \mathrm{t}_{\text {on }}
\end{aligned}
$$

For this model, $\mathrm{R}^{2}=99,7 \%$.

Similar screening study was done with factors associated to using conditions: voltage, current ant temperature. All these factors are known as significant but it was interesting to identify significant interactions and to know the effect of these factors on the two responses.

\section{Conclusion}

Screening studies permit calculating factors and interactions' effects and identifying significant elements. RSM study will permit establishing model composed by these factors and interactions.

Design of experiments is a very powerful method and is very interesting because of the two different investigations ways. It can be apply in many industrial regions on very complex problems thanks to optimal designs which allow constructing "à la carte" designs.

At this step of the work, influent elements on the responses are identified. Response Surface Method allows to find a polynomial model composed by influent elements. Anisotropic design area due to the presence of constrains induce the utilization of optimal designs to calculate the coefficients of the polynomial model show in (15). Optimum criterion used for this design of experiments is G-efficiency criteria with a critical limit fixed at $70 \%$.

This condition is obtained with 38 arrays. These constrains are defined by IGBT experts in order to not destroy the module during commutation tests.

The model deduces to RSM study will permit to find optimal arrangement of the factors in all the experimental area and not only for extremes of the centred and scaled values -1 and 1 of each factors.

\section{Acknowledgements}

This work was funded by ALSTOM which is gratefully acknowledged.

\section{References}

1. M. Ciappa, Selected failure mechanisms of modern power modules, Microelectronics Reliability, 42, 653-667 (2002).

2. J. Vallon, Introduction à l'étude de la fiabilité des cellules de commutation à IGBT sous fortes contraintes, thèse de l'INPT, (2003).

3. A. Hamidi, N. Beck, K. Thomas and E. Herr, Reliability and lifetime evaluation of different wire bonding technologies for high power IGBT modules, Microelectronics Reliability, 39, 1153-1158 (1999).

4. E. Herr, T. Frey, R. Schlegel, A. Struck and R. Zehringer, Substrate-to-base solder joint reliability in high power IGBT modules, Microelectronics Reliability, 37, 1719-1722 (1997).

5. A. Hamidi, G. Coquery, R. Lallemand, P. Vales and J.M. Dorkel, Temperature measurements and thermal modeling of high power IGBT multichip modules for reliability investigations in traction applications, Microelectronics Reliability, 38, 1353-1359 (1998).

6. M. Pillet, Les plans d'expériences par la méthode Taguchi, les Editions d'organisation, Paris (1997).

7. R.L. Plackett and J.P Burman, The design of optimum multifactorial experiments, Biometrika, 33(4), 305-325 (1946).

8. R.L. Rechtschaffner, Saturated fractions of $2 n$ and $3 n$ factorial designs, Technometrics, 9, 569-575 (1967).

9. G. Taguchi and S. Konishi, Orthogonal Arrays and Linear Graphs: Tools for Quality Engineering, Allen Park, MI: ASI Press, (1987).

10. J. Kiefer and J. Wolfowitz, Optimum designs in regression problems, Ann. of Math. Statist., 30, 271-294 (1959).

11. H.C. Srinivasaiah, and N. Bhat, Characterization of sub-100nm CMOS process using screening experiment 
technique, Solid-State Electronics, 49(3), 431-436 (2005).

12. G.E.P. Box and K.B. Behnken, On the experimental attainment of optimum conditions, Journal of the Royal Statistical Society, serie B, 13, 1-45 (1951).

13. G.E.P. Box and D.W. Behnken, Some new three level designs for study of quantitative variables, Technometrics, 2(4), 455-475 (1960).

14.D.H. Doehlert, Uniform shell designs, Journal of the Royal Statistical Society, serie C, 19, 231-239 (1970).

15. P.H. Chen, C. Yau, K.Y. Wu, S. Lin and H.C. Shih, Application of the Taguchi's design of experiment to optimize a bromine chemistrybased etching recipe for deep silicon trenches, Microelectronic Engineering, 77, 110-115 (2005).
16. Y. Dodge, Analyse de régression appliquée, Dunod, Ed. Paris, (1999).

17. A. Ben-Israel and T.N.E. Greville, Generalized inverses: theory and applications, John Wiley \& Sons, New-York, (1974).

18. C. Daniel, Use of half-normal plots in interpreting factorial two-level experiment, Technometrics, 1(4), 311-341 (1959).

19. R.V. Lenth, Quick and easy analysis of unreplicated factorials, Technometrics, 31(4), 469-473 (1989). 